\section{NOTIFICAÇÕES DE VIOLÊNCIA SEXUAL CONTRA A MULHER NO BRASIL}

\author{
Reporting of sexual violence against women in Brazil \\ Notificaciones de violencia sexual contra la mujer de Brasil
}

\section{RESUMO}

Objetivo: Apresentar o quadro de violência sexual contra a mulher no Brasil, com base nas notificações realizadas no Sistema de Informação de Agravos de Notificação (SINAN). Métodos: Trata-se de um estudo descritivo, com abordagem quantitativa, que analisou informações referentes às notificações de violência sexual contra a mulher, no período de 2009 a 2013, considerando a unidade da federação, perfil das mulheres, características da ocorrência e encaminhamentos realizados pelo setor saúde. Os dados foram analisados por meio da estatística descritiva, sendo apresentados números absolutos e relativos derivados das notificações. Resultados: No Brasil, foram registradas 21.871 notificações no período estudado. Observaram-se maiores taxas de registros no ano de 2013 e na região Norte. Predominou o ciclo de vida de 10 a 19 anos $(10.806 / 49,4 \%)$, as raças branca $(8.894 / 40,7 \%)$ e parda $(8.535 / 39,0 \%)$, e a escolaridade ensino fundamental incompleto $(5.444 / 24,9 \%)$. Os casos de violência sexual ocorreram com maior frequência na residência da mulher $(13.259 / 60,6 \%)$, com agressor conhecido $(5.649 / 25,8 \%)$ e sem suspeita do uso de álcool $(9.249 / 42,3 \%)$. A maior parte do atendimento no setor saúde foi de nível ambulatorial (15.842/72,6\%), e os casos evoluíram para alta (16.879/77,2\%). Conclusão: As notificações cresceram progressivamente no período estudado, e a violência sexual contra a mulher no país, registrada pelo setor saúde, atingiu, principalmente, adolescentes, no ambiente doméstico e com agressor conhecido.

Descritores: Violência Sexual; Violência contra a Mulher; Notificação; Vigilância em Saúde Pública.

\section{ABSTRACT}

Objective: To present the scenario of the sexual violence against women in Brazil, based on cases reported through the Notifiable Diseases Information System (Sistema de Informação de Agravos de Notificação - SINAN). Methods: This descriptive quantitative study analyzed the information on the reporting of sexual violence against women in the period from 2009 to 2013, including the federated state, the women's profile, the characteristics of the occurrences, and the referrals made by the health sector. Data was analyzed using descriptive statistics and presented in absolute and relative numbers derived from the cases reported. Results: In Brazil, 21.871 cases were reported in the studied period. The year 2013 and the Northern region presented the highest number of cases reported. There was a prevalence of 10- to 19-year lifecycle (10,806/49.4\%), white (8,894/40.7\%) and brown (8,535/39.0\%) races, incomplete primary education (5,444/24.9\%). Sexual assaults occurred most commonly in the woman's house $(13,259 / 60.6 \%)$, committed by an offender known to the victim, (5,649/25.8\%) and with no suspected use of alcohol (9,249/42.3\%). Most of the care provided by the health sector was on an outpatient basis (15,842/72.6\%), and the victims were discharged in most cases (16,879/77.2\%). Conclusion: Violence reports increased steadily in the studied period, and the sexual assault against women in the country, registered by the health sector, affected mainly the adolescents, in the home environment, and with an aggressor known to the victim.

Descriptors: Sexual Violence; Violence Against Women; Notice; Public Health Surveillance.
Artigo Original
1) Universidade de Fortaleza - UNIFOR Fortaleza (CE) - Brasil

Recebido em: 04/09/2015

Revisado em: 20/09/2015

Aceito em: 30/09/2015 


\section{RESUMEN}

Objetivo: Presentar el cuadro de la violencia sexual contra la mujer de Brasil basado en las notificaciones realizadas en el Sistema de Información de Agravios de Notificación (SINAN). Métodos: Se trata de un estudio descriptivo de abordaje cuantitativo que analizó las informaciones de las notificaciones de violencia sexual contra la mujer en el periodo entre 2009 y 2013 considerando la unidad de la federación, el perfil de las mujeres, las características de la ocurrencia y las prescripciones realizadas en el sector de salud. Los datos fueron analizados a través de la estadística descriptiva con números absolutos y relativos derivados de las notificaciones. Resultados: En Brasil fueron registradas 21.871 notificaciones en el período estudiado. Se observó mayores tasas de registros en el año 2013 y en la región Norte del país. Hubo el predominio del ciclo de vida entre 10 y 19 años (10.806/49,4\%), las razas blanca (8.894/40,7\%) y parda (8.535/39,0\%) y la educación primaria incompleta (5.444/24,9\%). Los casos de violencia sexual se dieron con más frecuencia en la residencia de la mujer (13.259/60,6\%), con agresor conocido (5.649/25,8\%) y sin sospecha de uso de alcohol (9.249/42,3\%). La mayor parte de la atención del sector de la salud fue a nivel de ambulatorio (15.842/72,6\%) y los casos evolucionaron para la alta (16.879/77,2\%). Conclusión: Las notificaciones crecieron progresivamente en el periodo estudiado y la violencia sexual contra la mujer en el país registrada en el sector de la salud, atingió principalmente a los adolescentes en el ambiente doméstico y con agresor conocido.

Descriptores: Violencia Sexual; Violencia contra la Mujer; Notificación; Vigilancia en Salud Pública.

\section{INTRODUÇÃO}

A violência sexual é uma das manifestações da violência de gênero contra a mulher mais cruel e persistente na história da humanidade. O fenômeno ignora fronteiras, configurando-se em um problema universal que atinge mulheres de diferentes países, culturas, classes sociais, raças, idades, estados civis e escolaridades, podendo ocorrer em qualquer lugar, tanto no espaço público como no privado, e ser perpetrado por estranhos ou por parceiros íntimos, parentes e conhecidos ${ }^{(1)}$.

A magnitude do fenômeno é revelada por investigações internacionais e nacionais. Estudo multipaíses da Organização Mundial da Saúde (OMS) revelou elevada prevalência e variabilidade do fenômeno: $6 \%$ a $59 \%$ quando cometida por parceiro íntimo e $0,3 \%$ a $12 \%$ por não parceiro $^{(2)}$. No cenário nacional, achados de pesquisa empreendida com 5.040 indivíduos mostram que a violência sexual por parceiro íntimo afetou $11,8 \%$ das mulheres, e que uma a cada dez relatou pelo menos uma ocorrência na vida $^{(3)}$. Dados do Anuário Brasileiro de Segurança Pública (2014) chamam atenção para a ocorrência de um estupro a cada 10 minutos no Brasil, tendo sido registrados 50.320 casos em $2013^{(4)}$.

A violência sexual assume um papel diferenciado no conjunto das violências de gênero, sobretudo pelas repercussões nas esferas física, sexual, reprodutiva e mental das mulheres, além dos impactos sociais. Nessa perspectiva, o fenômeno constitui-se um problema social que impacta de maneira significativa o modo de viver, adoecer e morrer das mulheres, sendo considerado mundialmente uma das principais formas de violação dos direitos humanos e um problema de saúde pública ${ }^{(1,5)}$.

Diante de sua alta prevalência e de seu impacto na vida de pessoas e coletividades, a violência sexual contra a mulher vem ganhando visibilidade, tornando-se alvo de discussões em diferentes campos disciplinares e por entidades internacionais, o que demandou a formulação de políticas e programas para seu enfrentamento, assim como a organização de práticas e serviços peculiares. No Brasil, no enfrentamento das violências, o setor saúde tem um papel chave na identificação, notificação, tratamento e encaminhamento dos casos. Particularmente em relação à violência sexual, o Ministério da Saúde vem realizando publicações com o propósito de apoiar as atividades dos profissionais de saúde no que diz respeito às definições, normas e protocolos de condutas ${ }^{(6)}$.

Dentre as estratégias de enfrentamento do problema, a notificação dessas situações se destaca, tendo em vista que o cumprimento dessa medida é fundamental para o dimensionamento da violência e de suas consequências, contribuindo para a elaboração de ações de intervenção. As bases legais para essa proposta foram estabelecidas pela Lei Federal $n^{\circ} 10.778$, em 24 de novembro de 2003, que estabeleceu a notificação compulsória, em todo o território nacional, dos casos de violência contra a mulher, atendida em serviços públicos e privados de saúde ${ }^{(7)}$. Em 2011, o Ministério de Saúde lançou a Portaria $n^{0}$ 104, que estabeleceu a violência doméstica, sexual e outras violências interpessoais como o $45^{\circ}$ evento de notificação compulsória $^{(8)}$

Para a padronização dos registros, foi instituída uma ficha de notificação no campo da vigilância em saúde, capilarizando para todos os serviços públicos de saúde do país a possibilidade de notificação. O registro dos dados ocorre no módulo do Sistema de Informação de Agravos de Notificação (SINAN), que é alimentado pelas Secretarias Municipais de Saúde (SMS) a partir das notificações realizadas. Essa padronização contribui para qualificar e sistematizar os registros, favorece uma maior acessibilidade aos dados consolidados, bem como permite a caracterização das violências ocorridas, os encaminhamentos realizados, entre outras informações, de acordo com as especificidades regionais $^{(9,10)}$. 
Vale ressaltar que esse processo de vigilância em saúde tem impacto fundamental nas estratégias de promoção da saúde, uma vez que a concepção ampliada de vigilância aspira intervir não apenas naquilo que se deve evitar, mas busca estabelecer patamares que devem ser alcançados, em termos de aquisições positivas do ponto de vista físico, mental, emocional, cultural, ambiental, para caracterizar uma boa qualidade de vida(11). Nessa perspectiva, o planejamento e o desenvolvimento de ações com base nesses índices permitem aos serviços acompanharem os casos de violência, bem como reivindicar mudanças políticas, envolvendo cumprimento de direitos, responsabilização, integração da rede de serviços, prevenção e promoção da saúde ${ }^{(12)}$.

Com base nesse contexto, este trabalho objetivou apresentar o quadro de violência sexual contra a mulher no Brasil, com base nas notificações realizadas no Sistema de Informação de Agravos de Notificação (SINAN). A partir da caracterização desse quadro, acredita-se que este estudo contribuirá no fornecimento de um panorama acurado desse problema de saúde pública, favorecendo a implementação de medidas de prevenção do fenômeno e promoção da saúde da mulher.

\section{MÉTODOS}

Trata-se de um estudo descritivo, de abordagem quantitativa, que teve como fonte de dados o Sistema de Informação de Agravos de Notificação (SINAN), o qual é alimentado pelas notificações e investigações de casos de doença e agravos que constam na relação de doenças, agravos e eventos de notificação compulsória, segundo a Portaria $n^{\circ} 104 / 2011^{(8)}$.

A coleta dos dados ocorreu em setembro de 2014, a partir de consultas ao endereço eletrônico do SINAN (http:// dtr2004.saude.gov.br/sinanweb/). Procurou-se localizar no SINAN as informações contidas na Ficha de Notificação/ Investigação de Violência Doméstica, Sexual e/ou outras Violências, que encampa a notificação de qualquer caso suspeito ou confirmado de violência doméstica, sexual e/ou outras violências contra homens e mulheres, independentemente de faixa etária( ${ }^{(8)}$.

$\mathrm{Na}$ seleção das notificações, incluíram-se aquelas relativas à violência sexual contra a mulher de todas as faixas etárias, no período de 2009 a 2013. As buscas na página eletrônica do SINAN geraram arquivos condensados das informações por ano, os quais foram importados para planilhas eletrônicas, para posterior análise. Para as variáveis consideradas no presente trabalho, realizou-se um consolidado de todo período estudado, somando-se manualmente o quantitativo obtido por ano.

Para a caracterização das violências sexuais contra a mulher, consideraram-se as variáveis que compõem a ficha de notificação: unidade da federação, faixa etária, escolaridade, raça, local de ocorrência, forma de agressão, características do agressor e encaminhamentos realizados pelo setor saúde.

No presente trabalho, analisaram-se os dados por meio da estatística descritiva, sendo apresentados números absolutos e relativos derivados das notificações de violência sexual contra a mulher. Taxas por cem mil mulheres foram calculadas para a variável unidade da federação, utilizandose a informação do número de mulheres em cada estado, segundo o censo $2010^{(13)}$. A discussão dos achados norteouse por documentos oficiais, políticas públicas e pela literatura sobre o tema.

Empreendeu-se o estudo exclusivamente com dados de acesso público, de forma que não foi necessária a apreciação por comitê de ética em pesquisa com seres humanos.

\section{RESULTADOS}

Em todo o país, registraram-se 21.871 notificações de violência sexual contra mulheres no período de 2009 a 2013, distribuídas segundo o ano: 1.726 (2009), 2.859 (2010), 4.261 (2011), 6.353 (2012) e 6.672 (2013). Observa-se um progressivo aumento das notificações no período, destacando-se o ano de 2013, com o maior número de registros (30,5\%) (Figura 1$)$.

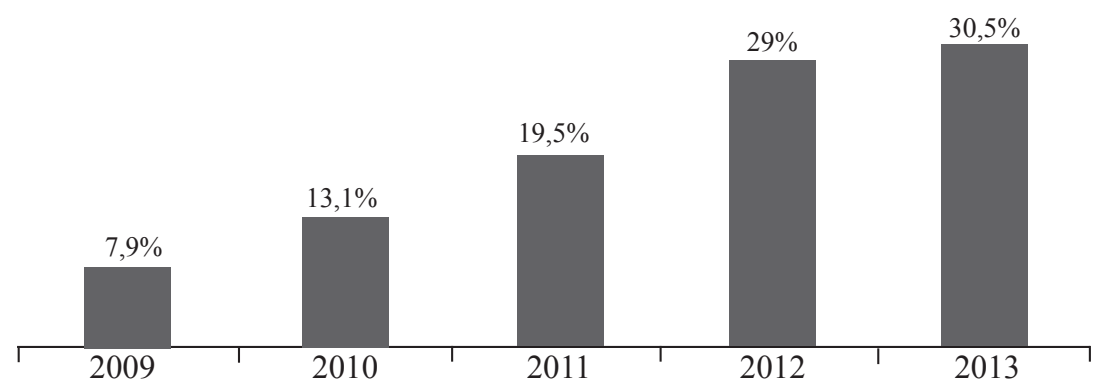

Figura 1 - Distribuição do percentual das notificações de violência sexual contra a mulher, segundo o ano. Brasil. (n=21.871). Fonte: SINAN/Ministério da Saúde (2009-2013). 
Na distribuição da taxa (por 100 mil mulheres) de notificações por unidade de federação (2009-2013), observaram-se as maiores taxas de registro, por ano, nos seguintes estados: 2009 - Roraima $(7,7)$ e Mato Grosso do Sul $(3,6) ; 2010$ - Roraima $(10,8)$ e Rio de Janeiro $(11,1)$; 2011 - Acre (33,4) e Mato Grosso (10,3); 2012 -Acre (54,5) e Piauí (24,9); 2013 - Acre $(70,9)$ e Piauí $(19,8)$ (Tabela I).
Ao analisar as características sociodemográficas das mulheres que vivenciaram situações de violência sexual no Brasil em todo período estudado, constata-se maior frequência do ato no ciclo de vida de 10 a 19 anos $(49,4 \%)$, das raças branca (40,7\%) e parda (39,0\%), e da escolaridade de $5^{\mathrm{a}}$ a $8^{\mathrm{a}}$ série incompleta $(24,9 \%)$. Vale destacar que $30,7 \%$ das notificações não registraram o item referente à escolaridade da mulher (Tabela II).

Tabela I - Distribuição do número e taxa de notificações de violência sexual contra a mulher, segundo a Unidade de Federação. Brasil. 2009-2013.

\begin{tabular}{|c|c|c|c|c|c|c|c|c|c|c|}
\hline \multirow{3}{*}{$\begin{array}{l}\text { Notificações } \\
\text { Total } \\
\text { Regiões/UF }\end{array}$} & \multirow{2}{*}{\multicolumn{2}{|c|}{$\begin{array}{l}2009 \\
1.726 \\
\end{array}$}} & \multirow{2}{*}{\multicolumn{2}{|c|}{$\begin{array}{c}2010 \\
2.859\end{array}$}} & \multirow{2}{*}{\multicolumn{2}{|c|}{$\begin{array}{c}2011 \\
4.261\end{array}$}} & \multirow{2}{*}{\multicolumn{2}{|c|}{$\begin{array}{l}2012 \\
6.353\end{array}$}} & \multirow{2}{*}{\multicolumn{2}{|c|}{$\begin{array}{l}2013 \\
6.672\end{array}$}} \\
\hline & & & & & & & & & & \\
\hline & n & Taxa & $\mathbf{n}$ & Taxa & n & Taxa & $\mathbf{n}$ & Taxa & $\mathrm{n}$ & Taxa \\
\hline \multicolumn{11}{|l|}{ Norte } \\
\hline Rondônia & 22 & 2,9 & 15 & 1,9 & 18 & 2,3 & 21 & 2,7 & 37 & 4,8 \\
\hline Acre & 13 & 3,5 & 16 & 4,5 & 122 & 33,4 & 199 & 54,5 & 259 & 70,9 \\
\hline Amazonas & 76 & 4,4 & 66 & 3,8 & 196 & 11,3 & 234 & 13,5 & 217 & 12,5 \\
\hline Roraima & 17 & 7,7 & 24 & 10,8 & 58 & 26,1 & 73 & 32,9 & 86 & 38,8 \\
\hline Para & 43 & 1,1 & 250 & 6,6 & 299 & 7,9 & 581 & 15,4 & 626 & 16,6 \\
\hline Amapá & 10 & 3,0 & 11 & 3,2 & 83 & 24,8 & 50 & 14,9 & 49 & 17,6 \\
\hline Tocantins & 02 & 0,2 & 12 & 1,7 & 27 & 3,9 & 43 & 6,3 & 96 & 14,1 \\
\hline \multicolumn{11}{|l|}{ Nordeste } \\
\hline Maranhão & 28 & 0,8 & 58 & 1,7 & 80 & 2,4 & 62 & 1,8 & 74 & 2,2 \\
\hline Piauí & 05 & 0,3 & 10 & 0,6 & 20 & 1,2 & 396 & 24,9 & 315 & 19,8 \\
\hline Ceara & 10 & 0,2 & 13 & 0,3 & 17 & 0,4 & 21 & 0,5 & 32 & 0,7 \\
\hline RG do Norte & 02 & 0,1 & 18 & 1,1 & 16 & 0,9 & 22 & 1,3 & 30 & 1,8 \\
\hline Paraíba & 08 & 0,4 & 12 & 0,6 & 13 & 0,7 & 29 & 1,5 & 20 & 1,0 \\
\hline Pernambuco & 147 & 3,2 & 136 & 3,0 & 310 & 6,8 & 319 & 7,0 & 260 & 5,7 \\
\hline Alagoas & 02 & 0,1 & 09 & 0,5 & 19 & 1,2 & 10 & 0,6 & 21 & 1,7 \\
\hline Sergipe & 26 & 2,4 & 53 & 5,0 & 85 & 8,0 & 121 & 11,4 & 112 & 10,5 \\
\hline Bahia & 27 & 0,4 & 177 & 2,5 & 52 & 0,7 & 71 & 1,0 & 197 & 2,7 \\
\hline \multicolumn{11}{|l|}{ Sudeste } \\
\hline Minas Gerais & 119 & 1,2 & 05 & 0,1 & 275 & 2,7 & 452 & 4,5 & 467 & 4,7 \\
\hline Espírito Santo & 14 & 0,8 & 115 & 6,4 & 51 & 2,8 & 118 & 6,6 & 156 & 8,7 \\
\hline Rio de Janeiro & 49 & 0,6 & 928 & 11,1 & 100 & 1,2 & 160 & 1,9 & 201 & 2,4 \\
\hline São Paulo & 599 & 2,8 & 189 & 0,9 & 1.100 & 5,2 & 1.493 & 7,5 & 1.186 & 5,6 \\
\hline \multicolumn{11}{|l|}{ Sul } \\
\hline Paraná & 102 & 2,0 & 67 & 1,3 & 228 & 4,3 & 358 & 6,7 & 462 & 8,7 \\
\hline Santa Catarina & 51 & 1,6 & 283 & 9,0 & 179 & 5,7 & 275 & 8,7 & 286 & 9,1 \\
\hline RG do Sul & 154 & 2,8 & 94 & 1,7 & 352 & 6,4 & 481 & 8,7 & 524 & 9,5 \\
\hline \multicolumn{11}{|l|}{ Centro Oeste } \\
\hline M. Grosso Sul & 45 & 3,6 & 17 & 1,4 & 82 & 6,7 & 142 & 11,5 & 137 & 11,1 \\
\hline Mato Grosso & 06 & 0,4 & 59 & 3,8 & 160 & 10,3 & 82 & 5,3 & 116 & 7,5 \\
\hline Goiás & 27 & 1,0 & 69 & 2,3 & 89 & 2,9 & 160 & 5,3 & 183 & 6,1 \\
\hline Distrito Federal & 26 & 1,2 & - & - & 51 & 3,8 & 120 & 9,0 & 202 & 15,0 \\
\hline Sem informação & 96 & - & 153 & - & 179 & - & 260 & - & 321 & - \\
\hline
\end{tabular}


Tabela II - Distribuição do número e proporção das notificações de violência sexual contra a mulher, segundo os dados sociodemográficos. Brasil. 2009-2013. $\mathrm{n}=21.871$

\begin{tabular}{lcc}
\hline Variáveis & $\mathbf{n}$ & $\mathbf{\%}$ \\
\hline Ciclo de vida & 7.098 & 32,4 \\
$<10$ anos & 10.806 & 49,4 \\
$10-19$ & 3.828 & 17,5 \\
$20-59$ & 130 & 0,6 \\
60 e mais & 05 & 0,1 \\
Sem informação & & \\
Raça & 8.894 & 40,7 \\
Branca & 1.781 & 8,1 \\
Preta & 168 & 0,8 \\
Amarela & 8.535 & 39,0 \\
Parda & 165 & 0,8 \\
Indígena & 2.328 & 10,6 \\
Sem informação & & \\
Escolaridade & 201 & 0,9 \\
Analfabeto & 2.639 & 12,1 \\
$1^{\text {a a 4 }}$ série incompleta & 899 & 4,1 \\
$4^{\mathrm{a}}$ série completa & 5.444 & 24,9 \\
$5^{\mathrm{a}}$ a $8^{\mathrm{a}}$ série incompleta & 826 & 3,8 \\
Fundamental completo & 1.579 & 7,2 \\
Médio incompleto & 1.050 & 4,8 \\
Médio completo & 337 & 1,5 \\
Superior incompleto & 228 & 1,0 \\
Superior completo & 8.668 & 39,7 \\
Sem informação & & \\
\hline
\end{tabular}

A Tabela III mostra as características da ocorrência. A maior parte dos casos de violência sexual ocorreu na residência da mulher $(60,6 \%)$ e sem repetição $(49,9 \%)$. Quanto ao meio utilizado pelo agressor para cometer a violência, o mais usado foi a força corporal/espancamento $(27,1 \%)$, seguido pela ameaça $(24,3 \%)$. As outras formas de agressão obtiveram pouca expressão.
Ao analisar as características do agressor, observou-se a não suspeita do uso de álcool (9.249/42,3\%) e o agressor conhecido $(5.649 / 25,8 \%)$ com mais frequência. Quanto ao encaminhamento realizado pelo setor saúde, evidenciouse que a maioria dos atendimentos à mulher foi a nível ambulatorial (15.842/72,6\%), e 77,2\% (16.879) dos casos evoluíram para alta. 
Tabela III - Distribuição do número e proporção das notificações de violência sexual contra a mulher, segundo as características da ocorrência. Brasil. 2009-2013. (n=21.871)

\begin{tabular}{|c|c|c|}
\hline Variáveis & $\mathbf{n}$ & $\%$ \\
\hline \multicolumn{3}{|l|}{ Local de ocorrência } \\
\hline Residência & 13.259 & 60,6 \\
\hline Habitação coletiva & 151 & 0,7 \\
\hline Escola & 401 & 1,8 \\
\hline Local de pratica esportiva & 104 & 0,5 \\
\hline Bar ou similar & 185 & 0,8 \\
\hline Via pública & 3.283 & 15,0 \\
\hline Comércio/Serviços & 274 & 1,3 \\
\hline Indústrias/construção & 97 & 0,4 \\
\hline Outros & 2.266 & 10,4 \\
\hline Sem informação & 1.851 & 8,5 \\
\hline \multicolumn{3}{|l|}{ Violência por repetição } \\
\hline Sim & 7.113 & 32,5 \\
\hline Não & 10.904 & 49,9 \\
\hline Sem informação & 3.854 & 17,6 \\
\hline \multicolumn{3}{|l|}{ Força corporal/espancamento } \\
\hline $\mathrm{Sim}$ & 5.919 & 27,1 \\
\hline Não & 14.675 & 67,1 \\
\hline Sem informação & 1.277 & 5,8 \\
\hline \multicolumn{3}{|l|}{ Enforcamento } \\
\hline Sim & 155 & 0,7 \\
\hline Não & 20.718 & 94,7 \\
\hline Sem informação & 998 & 4,6 \\
\hline \multicolumn{3}{|l|}{ Objeto contundente } \\
\hline Sim & 140 & 0,6 \\
\hline Não & 20.707 & 94,7 \\
\hline Sem informação & 1.024 & 4,7 \\
\hline \multicolumn{3}{|l|}{ Substância Objeto quente } \\
\hline $\operatorname{Sim}$ & 50 & 0,2 \\
\hline Não & 20.817 & 95,2 \\
\hline Sem informação & 1.004 & 4,6 \\
\hline \multicolumn{3}{|l|}{ Envenenamento } \\
\hline Sim & 64 & 0,3 \\
\hline Não & 20.785 & 95,0 \\
\hline Sem informação & 1.022 & 4,7 \\
\hline \multicolumn{3}{|l|}{ Arma de fogo } \\
\hline Sim & 955 & 4,4 \\
\hline Não & 19.871 & 90,8 \\
\hline Sem informação & 1.045 & 4,8 \\
\hline \multicolumn{3}{|l|}{ Ameaça } \\
\hline Sim & 5.300 & 24,3 \\
\hline Não & 15.206 & 69,5 \\
\hline Sem informação & 1.347 & 6,2 \\
\hline
\end{tabular}

\section{DISCUSSÃO}

Ao se analisarem os dados obtidos no presente estudo, evidenciou-se que o número de notificações de violência sexual contra a mulher aumentou de forma gradativa no período estudado no país. Essa constatação gera algumas reflexões: o número de casos de violência sexual aumentou com os anos ou os profissionais de saúde estão mais sensibilizados e capacitados para realizarem a notificação?

Percebe-se o investimento na divulgação dos instrumentos legais, como o Estatuto da Criança e do Adolescente (ECA); a Lei no 10.778 de 2003, que tornou 
obrigatória a notificação compulsória de violência contra a mulher nos serviços de saúde públicos e privados; e a Portaria $\mathrm{n}^{\mathrm{o}} 104$ de 2011, que dispõe a violência doméstica, sexual e/ou outras violências como o $45^{\circ}$ evento de notificação compulsória ${ }^{(14)}$. Os estados estão empreendendo esforços na perspectiva de implementar a ficha de notificação nos serviços de saúde, sensibilizando os profissionais por meio de capacitações e treinamentos ${ }^{(15,16)}$. Assim como se verifica maior disseminação da temática nos meios de comunicação e na produção científica ${ }^{(17,18)}$. Esses fatores favorecem a visibilidade do tema, o que pode ter influenciado no aumento da quantidade de notificações nos últimos anos.

Por outro lado, apesar desses investimentos e do aumento no número de notificações, pesquisas revelam que a prática notificatória da violência ainda acontece de forma incipiente e as notificações realizadas não correspondem à real incidência dos $\operatorname{casos}^{(15,16,19)}$. Nessa perspectiva, tornam-se necessários maiores empenhos para a concreta incorporação da notificação na prática profissional, uma vez que a violência é uma questão complexa e somente a mera distribuição das fichas nos serviços de saúde não é suficiente para uma atuação efetiva frente ao fenômeno ${ }^{(19)}$.

No presente trabalho, observou-se a discrepância das notificações de violência sexual contra a mulher, segundo as unidades da federação, o que pode revelar especificidades locais que parecem ser atravessadas por questões socioculturais, sobretudo políticas ${ }^{(15)}$. Chama muita atenção, na atual investigação, o fato de os estados da região Norte serem os que têm maiores taxas de notificação, além de tais índices terem aumentado de maneira progressiva com os anos. Com relação a isso, indaga-se se nessa região ocorrem mais casos de violência sexual ou se o processo de notificação está mais consolidado nessas localidades.

A região Norte, em decorrência de suas características socioeconômicas, apresenta significativos índices de violência sexual contra a mulher, principalmente dirigida às adolescentes ${ }^{(20)}$. Nos locais de garimpo, ocorre alta concentração de pontos de prostituição infantil, nos quais as meninas entre 12 e 19 anos se encontram em regime de escravidão e são forçadas a se prostituir. A exploração de mulheres, crianças e adolescentes se desenvolve expressivamente em prostíbulos fechados, onde a exploração se relaciona ao mercado regionalizado das práticas extrativistas ${ }^{(20)}$.

Outra possibilidade de compreensão quanto ao maior número de casos notificados nessa região pode estar relacionada à evolução na oferta de equipamentos de apoio à mulher em situação de violência sexual, ao fortalecimento da rede de serviços ${ }^{(20)}$, além do investimento em capacitações dos profissionais para a efetivação do registro dos casos de violência nos instrumentos formais ${ }^{(16)}$.
Quanto às variáveis sociodemográficas, verificouse, na presente pesquisa, que a violência sexual contra a mulher ocorre mais no ciclo de vida de 10 a 19 anos, atingindo, portanto, mais adolescentes, considerando os critérios da Organização Mundial da Saúde $(\mathrm{OMS})^{(21)}$. O predomínio dessa faixa etária também foi verificado em outras pesquisas internacionais e nacionais. Um estudo com 1.242 meninas e mulheres, de 13 a 24 anos, na Suazilândia, país na África Austral, constatou que 33,2\% delas relataram terem vivenciado episódio de violência sexual antes dos 18 anos de idade $^{(22)}$. Outra investigação evidenciou que adolescentes entre 10 e 12 anos incompletos foram as que mais sofreram violência sexual, seguido pelo período de 12 a 14 anos completos ${ }^{(23)}$.

A realidade dos casos de violência sexual contra adolescentes encontrada nas informações das fichas de notificação do setor saúde pesquisadas neste trabalho também tem sido observada em fontes de registros de outros setores da rede de atendimento. Estudo realizado com os dados do Conselho Tutelar constatou que 90\% dos casos de violência sexual ocorreram na faixa etária de 10 a 13 anos $^{(24)}$. Pesquisadores ${ }^{(25)}$, ao caracterizarem os atendimentos de um Centro de Referência que acolhe crianças e adolescentes em situação de violência sexual no Rio Grande do Sul, mostraram que $75 \%$ dos casos eram do sexo feminino, com idade entre 5 e 12 anos.

Os resultados do presente trabalho também indicam maior ocorrência de violência sexual em mulheres da raça branca e parda, com ensino fundamental incompleto - compatível com o ciclo de vida mais prevalente. Esses dados confirmam o que a literatura vem apontando sobre a caracterização da violência contra a mulher ${ }^{(16,26,27)}$.

Também se observou no presente estudo que a violência sexual acontece, predominantemente, na residência da mulher. No ambiente doméstico, os limites impostos pela privacidade isolam a família dos olhos e ouvidos do domínio público, proporcionando aos agressores um local no qual a violência sexual torna-se um crime perfeito, já que pode ser praticada sem testemunhas ou encoberta pela privacidade do $1 \operatorname{lar}^{(28)}$.

Este fato também pode ser atribuído às questões de gênero que ainda permanecem enraizadas fortemente nas relações entre os sexos, colocando a mulher em posição secundária em relação ao homem, o que pode levar ao aumento da violência sexual em âmbito doméstico pelo próprio companheiro. Pesquisas ${ }^{(23,29)}$ indicam a relação entre as desigualdades de gênero com a violência sexual, principalmente contra crianças e adolescentes, tendo em vista que as motivações dos agressores não têm origem apenas no desejo, mas abrangem questões relacionadas ao poder do indivíduo mais experiente, que assume a posição 
de dominador em relação ao mais jovem e inexperiente ${ }^{(23,29)}$. Nesse contexto, argumenta-se ${ }^{(29)}$ que crianças e adolescentes encontram-se em fase de desenvolvimento psicossocial, cuja imaturidade não permite compreender a teia criada pelo perpetrador, o qual impõe autoridade para concretizar a sedução e a prática sexual ${ }^{(29)}$.

Confirmando o exposto, os agressores mais prevalentes no presente estudo foram os conhecidos das mulheres. Esses achados sinalizam o alto impacto da violência perpetrada por conhecidos, como familiares, amigos e vizinhos, com acesso ao domicílio e convívio social dessas mulheres; e estão em consonância com outras investigações ${ }^{(16,29)}$.

Apesar do predomínio de agressores conhecidos, pesquisas pontuam que a identidade do agressor é diferente em estatísticas de estudos realizados com dados de delegacias ou serviços de saúde, quando comparadas com investigações populacionais. Estudiosos ${ }^{(26)}$ observaram que, ao longo dos anos, houve um aumento no número de agressores conhecidos, mas ainda há um predomínio de agressores desconhecidos em $65 \%$ dos casos de violência sexual relatados. Essa diferença pode indicar que a agressão sexual por um desconhecido difere bastante do mesmo ato cometido por uma pessoa próxima, havendo a tendência de as mulheres denunciarem, com mais frequência, às autoridades policiais e buscarem os serviços de saúde nas situações em que o agressor é um desconhecido ${ }^{(30)}$.

Segundo os resultados do presente trabalho, na maior parte dos casos notificados não houve o consumo de álcool pelo agressor. No entanto, outra pesquisa chama atenção que a ingestão do álcool pode representar um fator precipitante da violência, pelo efeito desinibidor da conduta dos agressores ou como um meio de minimizar a responsabilidade pelo comportamento violento ${ }^{(31)}$.

Quanto à abordagem da mulher em situação de violência sexual pelo setor saúde, evidenciou-se no presente estudo que a maioria dos atendimentos foi de nível ambulatorial e os casos evoluíram para alta. O tipo de atendimento dispensado pelo setor saúde às mulheres é reflexo da intensidade das lesões físicas provocadas pelo ato ${ }^{(32)}$. Contudo, vale ressaltar que poucas mulheres agredidas sexualmente sofrem traumas físicos severos ${ }^{(6)}$.

Por outro lado, a violência sexual resulta em grande impacto na vida social e psíquica das que a sofreram, assim como repercute nas relações familiares ${ }^{(33)}$. Dessa forma, a mulher/adolescente que vivenciou essa situação requer um acompanhamento sistemático por parte dos serviços de saúde, tendo em vista os impactos físicos e psicológicos provocados pelo ato ${ }^{(6)}$. Nos casos de violência sexual praticada por conhecidos ou pessoas próximas, é importante considerar que as mulheres/adolescentes podem estar mais vulneráveis, pelo envolvimento emocional, dependência econômica, medo de represálias ou repetição da violência. Nessa compreensão, torna-se imperioso a qualificação dos profissionais que atuam na rede de atendimento, para que estes possam promover uma atenção na perspectiva integral $^{(6)}$.

Vale mencionar o significativo número do item "sem informação", constatado no atual estudo, nos aspectos que compõem a ficha de notificação, o que sinaliza uma fragilidade no preenchimento. A completude no preenchimento dos campos da ficha e a adesão de profissionais de saúde são considerados pontos críticos do Sistema de Vigilância associado à subnotificação dos dados ainda existentes ${ }^{(29)}$

As informações não registradas comprometem uma análise mais minuciosa das violências, trazendo prejuízos à revelação da magnitude e das características dos casos, o que pode inviabilizar a adoção de estratégias efetivas de enfrentamento do fenômeno. Diante dessa realidade, tornase necessário o investimento em capacitação profissional para o manejo dos casos de violência, para a efetivação da notificação e qualidade dos registros ${ }^{(34)}$.

Além da fragilidade no preenchimento da ficha de notificação, assume-se como limitação deste estudo o fato de os dados gerados pelo SINAN poderem não refletir a magnitude real da violência sexual contra a mulher no país, tendo em vista a subnotificação pelos entraves ao ato de notificar as expressões de violência ${ }^{(15,34)}$.

Contudo, os resultados da presente investigação sinalizam o panorama do fenômeno, e esse perfil da violência sexual contra a mulher mostra-se imprescindível para o acionamento das ações de promoção da saúde voltadas para a prevenção do problema e o estímulo à cultura da paz.

\section{CONCLUSÃO}

Em conclusão, foi evidenciado que o número de notificações cresceu de forma progressiva no período estudado e que a região Norte foi a que mais notificou casos de violência sexual contra a mulher. Predominaram mulheres com idade entre 10 e 19 anos, das raças branca e parda, e com baixa escolaridade, sendo a residência o principal local de ocorrência e agressor conhecido. Na maior parte dos casos, realizou-se atendimento ambulatorial pelo setor saúde, resultando em alta.

\section{REFERÊNCIAS}

1. Contreras JM, Bott S, Guedes A, Dartnall E. Violência sexual na América Latina e no Caribe: uma análise de dados secundários. Iniciativa de Pesquisa sobre Violência Sexual; 2010. 
2. Garcia-Moreno C, Henrica AFM, Watts C, Ellsberg M, Heisi L. Estudio multipaís de la OMS sobre salud de la muer y violência doméstica contra la mujer: primeros resultados sobre prevalencia, eventos relativos la salud y respuestas de las mujeres a dicha violencia. Ginebra: Organización Mundial de la Salud; 2005.

3. Schraiber LB, D'oliveira AFPL, França Junior I. Violência sexual por parceiro íntimo entre homens e mulheres no Brasil urbano, 2005. Rev Saúde Pública. 2008;42(Supl 1):127-37.

4. Fórum Brasileiro de Segurança Pública. Anuário Brasileiro de Segurança Pública, 2014. São Paulo: Fórum Brasileiro de Segurança Pública; 2014.

5. Organização Panamericana de Saúde - OPS. Comprender y abordar la violencia contra las mujeres: violencia sexual. Washington: OPS; 2013.

6. Ministério da Saúde (BR). Prevenção e tratamento dos agravos resultantes da violência sexual contra mulheres e adolescentes: norma técnica. Brasília: Ministério da Saúde; 2012.

7. Presidência da República (BR). Lei $\mathrm{n}^{\circ}$ 10.778, de 24 de novembro de 2003. Estabelece a notificação compulsória, no território nacional, do caso de violência contra a mulher que for atendida em serviços de saúde públicos ou privados [acesso 2015 Abr 14]. Disponível em: http://www.abenfomg.com.br/site/ arquivos/outros/09_lei_de_notificacao_violencia.pdf.

8. Ministério da Saúde (BR). Portaria $n^{\circ}$ 104, de 25 de janeiro de 2011. Define as terminologias adotadas em legislação nacional, a relação de doenças, agravos e eventos em saúde pública de notificação compulsória em todo território nacional e estabelece fluxos, critérios, responsabilidades e atribuições aos profissionais de saúde. Brasília: Ministério da Saúde; 2011.

9. Lima JS, Deslandes SF. A notificação compulsória do abuso sexual contra crianças e adolescentes: uma comparação entre os dispositivos americanos e brasileiros. Interface Comun Saúde e Educ. 2012;15(38):819-32.

10. Lima JS, Deslandes SF. Olhar da gestão sobre a implantação da ficha de notificação da violência doméstica, sexual e/outras violências em uma metrópole do Brasil. Saúde Soc. 2015;24(2):661-73.

11. Ayres JRCM. Epidemiologia, promoção da saúde e o paradoxo do risco. Rev Bras Epidemiol. 2002;5(Supl 1):28-42.

12. Ferreira AL, Souza ER. Análise de indicadores de avaliação do atendimento a crianças e adolescentes em situação de violência. Cad Saúde Pública. 2008;24(1):28-38.

13. Instituto Brasileiro de Geografia e Estatística - IBGE. Censo Demográfico 2010 [acesso em 2015 Jan 10]. Disponível em: http://www.ibge.gov.br/home/ estatistica/populacao/censo2010/default.shtm

14. Lima CA, Deslandes SF. Violência sexual contra mulheres no Brasil: conquistas e desafios do setor saúde na década de 2000. Saúde Soc. 2014;23(3):787800 .

15. Assis SG, Avanci JQ, Pesce RP, Pires TO, Gomes DL. Notificações de violência doméstica, sexual e outras violências contra crianças no Brasil. Ciênc Saúde Coletiva. 2012;17(9):2305-17.

16. Veloso MMX, Magalhães CMC, Dell'Aglio DD, Cabral IR, Gomes MM. Notificação da violência como estratégia de vigilância em saúde: perfil de uma metrópole do Brasil. Ciênc Saúde Coletiva. 2013;18(5):1263-72.

17. Scarpati AS, Rosa EM, Guerra VM. Representações sociais da violência sexual na produção científica nacional. Psicol Argum. 2014;32(77):9-18.

18. Augusto AO, Lima VLA, Sena LX, Silva AF, Gomes VR, Santos ACB. Mapeamento dos casos de violência contra a mulher na região metropolitana de Belém narrados pela mídia impressa do estado do Pará. Rev Para Med. 2015;29(2):23-32.

19. Moreira GAR, Vieira LJS, Deslandes SF, Pordeus MAJ, Gama IS, Brilhante AVM. Fatores associados à notificação de maus-tratos em crianças e adolescentes na atenção básica. Ciênc Saúde Coletiva. 2014;19(10):4267-76.

20. Souza CM, Adesse L. Violência sexual no Brasil: perspectivas e desafios. Brasília: Secretaria Especial de Políticas para as Mulheres; 2005.

21. Organização Mundial da Saúde - OMS. Salud para los adolescentes del mundo: una segunda oportunidad en la segunda década. Genebra: OMS; 2014.

22. Reza A, Breiding MJ, Gulaid J, Mercy JA, Blanton C, Mthethwa Z, et al. Sexual violence and its health consequences for female children in Swaziland: a cluster survey study. Lancet. 2009;373(9679):1966-72.

23. Ribeiro MP, Ferriani MGC, Reis JN. Violência sexual contra crianças e adolescentes: características relativas à vitimização nas relações familiares. Cad Saúde Pública. 2004;20(2):456-64.

24. Costa MCO, Carvalho RC, Bárbara JFRS, Santos CAST, Gomes WA, Sousa HL. O perfil da violência 
contra crianças e adolescentes, segundo registros de Conselhos Tutelares: vítimas, agressores e manifestações de violência. Ciênc Saúde Coletiva. 2007;12(5):1129-41.

25. Pelisoli C, Pires JPM, Almeida ME, Dell'Aglio DD. Violência sexual contra crianças e adolescentes: dados de um serviço de referência. Temas Psicol. 2010;18(1):85-97.

26. Oshikata CT, Bedone AJ, Papa MSF, Santos GB, Pinheiro CD, Kalies AH. Características das mulheres violentadas sexualmente e da adesão ao seguimento ambulatorial: tendências observadas ao longo dos anos em um serviço de referência em Campinas, São Paulo, Brasil. Cad Saúde Pública. 2011;27(4):701-13.

27. Vieira EM, Perdona GSC, Santos MA. Fatores associados à violência física por parceiro íntimo em usuárias de serviços de saúde. Rev Saúde Pública. 2011;45(4):730-7.

28. Galvão EF, Andrade SM. Violência contra a mulher: análise de casos atendidos em serviço de atenção à mulher em município do Sul do Brasil. Saúde Soc. 2004;13(2):89-99.

29. Souza CS, Costa COM, Assis SG, Musse JO, Nascimento Sobrinho C, Amaral MTR. Sistema de Vigilância de Violências e Acidentes/VIVA e a notificação da violência infanto-juvenil, no Sistema Único de Saúde/SUS de Feira de Santana-Bahia, Brasil. Ciênc Saúde Coletiva. 2014;19(3):773-84.
30. Campos MAMR, Schor N, Anjos RMP, Laurentiz JC, Santos DV, Peres F. Violência Sexual: integração saúde e segurança pública no atendimento imediato à vítima. Saúde Soc. 2005;14(1):101-9.

31. Moura LBA, Gandolfi L, Vasconcelos AMN, Pratesi R. Violências contra mulheres por parceiro íntimo em área urbana economicamente vulnerável, Brasília, DF. Rev Saúde Pública. 2009;43(6):944-53.

32. Krug EG, Dahlberg LL, Mercy JA, Zwi A, Lozano R, editores. Relatório mundial sobre violência e saúde. Genebra: OMS; 2002.

33. Organização Panamericana de Saúde - OPAS. Comprender y abordar la violencia contra las mujeres: Violencia sexual. Washington: OPAS; 2013.

34. Sousa MH, Bento SF, Osis MJD, Ribeiro MP, Faúndes A. Preenchimento da notificação compulsória em serviços de saúde que atendem mulheres que sofrem violência sexual. Rev Bras Epidemiol. 2015;18(1):94107.

\section{Endereço para correspondência:}

Gracyelle Alves Remigio Moreira

Universidade de Fortaleza

Programa de Pós-Graduação em Saúde Coletiva

Av. Washington Soares, 1321/ Bloco S, Sala S1

Bairro Edson Queiroz

CEP 60811-905- Fortaleza - CE - Brasil

E-mail: gracyremigio@gmail.com 